\title{
Notch ligand Delta-like 1 promotes the metastasis of melanoma by enhancing tumor adhesion
}

\author{
J.P. Zhang ${ }^{1 *}$, N. Li ${ }^{2 *}$, W.Z. Bai ${ }^{1}$, X.C. Qiu ${ }^{1}$, B.A. Ma ${ }^{1}$, Y. Zhou ${ }^{1}$, Q.Y. Fan ${ }^{1}$ and L.Q. Shan ${ }^{1}$ \\ ${ }^{1}$ Department of Orthopedic Surgery, Tangdu Hospital, The Fourth Military Medical University, Xi'an, China \\ ${ }^{2}$ Department of Oncology, Tangdu Hospital, The Fourth Military Medical University, Xi'an, China
}

\begin{abstract}
Notch signaling plays a vital role in tumorigenicity and tumor progression by regulating proliferation, invasion, and the tumor microenvironment. Previous research by our group indicated that Notch ligand Delta-like 1 (DIl1) is involved in angiogenesis in melanoma, and we noticed that it took a longer time to trypsinize Dll1-expressing B16 melanoma cells than the control cells. In this article, we extended our study to investigate the effects of DIl1 on tumor cell adhesion and metastasis. DII1 overexpression activated Notch signaling in B16 tumor cells and significantly enhanced the adhering capacity of B16 tumor cells both in vitro and in vivo. B16-DIl1 cells also had a higher metastatic potential than their counterpart in the mouse model of lung metastasis. Along with increased DII1 expression, N-cadherin, but not E-cadherin, was upregulated in B16-DII1 cells. These data suggested that Notch ligand DII1 may enhance the adhesion and metastasis of melanoma cells by upregulation of $\mathrm{N}$-cadherin.
\end{abstract}

Key words: Delta-like 1; Notch signaling; Melanoma; Metastasis; Adhesion; N-cadherin

\section{Introduction}

Metastasis is the key factor in determining the stage, relevant treatment, and prognosis of most solid cancers. Although metastasis only occurs in approximately $10 \%$ of melanoma patients, it remains the major cause of death (1). The lungs are the most common site of metastasis in melanoma (2). Tumor metastasis is a complex process that includes local invasion, intravasation, and survival in the circulation, extravasation, and colonization. The tumor cells must overcome numerous hurdles to successfully colonize in the target organ $(3,4)$. In fact, the circulation system is such a tough environment that only $0.01 \%$ of the circulating tumor cells can survive to produce metastasis (4). The adhesion of circulating tumor cells to vascular endothelial cells is one of the key steps for metastasis because it can protect tumor cells from anoikis, fluid shear force, and attack from the immune system (5). Many adhesion molecules, such as those from the integrin or cadherin family, participate in the attachment process of tumor cells and have been reported to facilitate growth and transmigration of tumor cells (5).
Notch signaling is an evolutionarily conserved pathway that controls cell fate determination, cellular differentiation, and pattern formation in many tissue types by ligand-receptor interactions with neighboring cells. There are four Notch receptors (Notch1-4) and five ligands [Jagged1, Jagged2, and Delta-like ligands (DII) 1, 3, and 4]. Upon activation of the Notch receptor, the intracellular domain of the receptor is cleaved, and it can subsequently translocate to the nucleus, where it interacts with the transcription factor $\mathrm{C}$ promoter-binding factor $1 /$ recombination signal binding protein $\mathrm{J} / \mathrm{\kappa}(\mathrm{RBP}-\mathrm{J})$ to activate target genes such as Hes family basic helix-loop-helix members (6).

Notch signaling is implicated in various neoplastic processes. Depending on organ and tissue type, Notch signaling can function either as a promoter to support tumor development or as a suppressor to inhibit tumor growth (7-10). In melanoma, it has been seen that activation of the Notch pathway is involved in the tumorigenic process $(11,12)$. Pinnix et al. (13) demonstrated that activation of Notch1 conferred transforming

Correspondence: L.Q. Shan and/or Q.Y. Fan, Department of Orthopedic Surgery, Tangdu Hospital, The Fourth Military Medical University, Xi'an 710038, China. E-mail: drshanlq@fmmu.edu.cn and/or bonetm@fmmu.edu.cn

${ }^{*}$ These authors contributed equally to this study.

Received July 17, 2013. Accepted January 13, 2014. First published online March 31, 2014. 
properties, such as increased proliferative capacity and unregulated cell adhesion and migration, to melanocytes. It has also been found that Notch1 is a key effector of the oncogene Akt and hypoxia in melanoma development, and it can facilitate melanoma development by maintaining cell proliferation and protecting cells from stressinduced cell death (14). Overexpression of Notch1 can also increase the aggressiveness of primary melanoma cells through upregulation of $\beta$-catenin or $\mathrm{N}$-cadherin $(15,16)$.

Previously, our group investigated the effects of the Notch 1 ligand DII1 on angiogenesis and tumor growth in melanoma and found that overexpression of Dll1 promoted tumor cell proliferation in vitro (17), but reduced tumor growth in vivo. Interestingly, it took a longer time to trypsinize Dll1-expressing B16 melanoma cells than the control cells. Thus, we hypothesized that DIl1 may have some effects in regulating the adhesion of melanoma cells. In the present study, we extended our research to evaluate the role of DIl1 in tumor adhesion and metastasis.

\section{Material and Methods}

\section{Cell culture}

DII1-overexpressing (B16-DII1) and control (B16-GFP, green fluorescent protein) mouse melanoma cells that express GFP were established as previously described (17) and were maintained in RPMI 1640 medium supplemented with $10 \%$ fetal calf serum, $100 \mathrm{U} / \mathrm{mL}$ penicillin, and $100 \mu \mathrm{g} / \mathrm{mL}$ streptomycin (Life Technologies, USA). Human umbilical vein endothelial cells (HUVECs) were isolated after treatment of umbilical veins with collagenase and were maintained in complete Medium 199 (M199; Gibco-BRL, USA) supplemented with $20 \%$ fetal calf serum, $100 \mathrm{U} / \mathrm{mL}$ penicillin, $100 \mu \mathrm{g} / \mathrm{mL}$ streptomycin, $0.25 \mathrm{mg} / \mathrm{mL}$ amphotericin B, $16 \mathrm{U} / \mathrm{mL}$ heparin, $75 \mathrm{mg} / \mathrm{mL}$ endothelial cell growth supplement, and $2 \mathrm{mM}$ glutamine. All cells were grown at $37^{\circ} \mathrm{C}$ in a humidified atmosphere with $5 \% \mathrm{CO}_{2}$ and subcultured by trypsinization with $0.05 \%$ trypsin- $0.02 \%$ EDTA when the cells grew to confluence.

\section{Quantitative real-time RT-PCR}

Total RNA was isolated using Trizol reagent (Invitrogen, USA) following the manufacturer's instructions. Complementary DNA was prepared with a reversetranscription kit from Toyobo (Japan). RT-PCR was performed using a kit (SYBR Premix EX Taq, Takara, Japan) and the ABI PRISM 7300 real-time PCR system, with $\beta$-actin as the internal control. The following primers were used: $\beta$-actin, $5^{\prime}$-CATCCGTAAAGACCTCTATGCCAAC-3' and 5'-ATGGAGCCACCGATCCACA-3'; DII1, 5' AGGGTGTGATGACCAACATGGA-3' and 5'-TATCGGATGCACTCATCGCAGTA-3'; Hes1, 5'-GCAGACATTCTGGAAATGACTGTGA-3' and 5'-GAGTGCGCACCTC-
GGTGTTA-3'; E-cadherin, 5'-GAAAGCGGCTGATACTGACC-3' and 5'-CGTACATGTCAGCCGCTTC-3'; and N-cadherin, 5'-TGTTTGACTATGAAGGCAGTGG-3' and 5'-TCAGTCATCACCTCCACCAT-3'.

\section{Western blot}

Cultured tumor cells were lysed in a radioimmunoprecipitation assay buffer (RIPA, $50 \mathrm{mM}$ Tris- $\mathrm{HCl}, 150 \mathrm{mM}$ $\mathrm{NaCl}, 1 \mathrm{mM} \mathrm{MgCl} 2,0.5 \%$ octylphenoxypolyethoxyethanol, $0.1 \mathrm{mM}$ phenylmethylsulfonyl fluoride). Protein concentration in the extracts was determined using a bicinchoninic acid (BCA) protein assay (Pierce, USA) according to the manufacturer's instructions. The samples were separated by SDS-12\% polyacrylamide gel electrophoresis and transferred to polyvinylidene difluoride membranes (PVDF; Hybond-P, Amersham Biosciences, USA). Blots were blocked with $5 \%$ non-fat milk in TBS-T buffer for $1 \mathrm{~h}$ at room temperature and then probed using the appropriate primary antibodies followed by horseradish peroxidase-conjugated rabbit anti-goat or goat antirabbit IgG antibodies. The primary antibodies included goat polyclonal IgG antibody to DII1 and rabbit polyclonal IgG antibodies to Hes1, N-cadherin, or E-cadherin (Santa Cruz Biotechnology, USA). $\beta$-actin was detected simultaneously using 1:5000 dilution of monoclonal mouse anti$\beta$-actin antibody (Sigma, USA) as a loading control. The membrane was developed using chemiluminescent reagents (Super Signal West Femto Maximum Sensitivity Substrate, Pierce).

\section{Tumor cell adhesion assays}

For plate adhesion assays, tumor cells $\left(4 \times 10^{4} /\right.$ well $)$ were seeded on flat-bottom 96 -well plates and incubated at $37^{\circ} \mathrm{C}$ for $30 \mathrm{~min}$ or $1 \mathrm{~h}$. The plates were then gently washed three times with PBS, and fresh medium containing $20 \% 5 \mathrm{mg} / \mathrm{mL}$ 3-(4,5-dimethylthiazol-2-yl)2,5-diphenyltetrazolium bromide (MTT) was added. After a further incubation at $37^{\circ} \mathrm{C}$ for $4 \mathrm{~h}$, the medium was removed, and $150 \mu \mathrm{L}$ dimethyl sulfoxide (Sigma) was added to each well. The absorbance of each well was measured at $490 \mathrm{~nm}$ after thorough shaking for $10 \mathrm{~min}$.

For adhesion assays using endothelial cells, suspensions of HUVECs in M199 were seeded onto 12-well plates at a density of $2 \times 10^{5} /$ well. After the cells grew to confluence, the plates were washed with PBS. Then, $5 \times 10^{4}$ tumor cells in a volume of $2 \mathrm{~mL}$ RPMI 1640 medium were added into individual wells containing monolayers of HUVECs. The tumor cells were incubated with HUVECS for $1 \mathrm{~h}$ at $37^{\circ} \mathrm{C}$. The wells were then gently washed 3 times with PBS to remove unbound tumor cells. After trypsinization, single cell suspensions were resuspended in PBS containing $2 \%$ fetal calf serum and $0.05 \%$ $\mathrm{NaN}_{3}$. The cells were subsequently incubated with $5 \mu \mathrm{L}$ propidium iodide for $30 \mathrm{~min}$ in the dark at room temperature and analyzed using flow cytometry (FACSCalibur, 
A

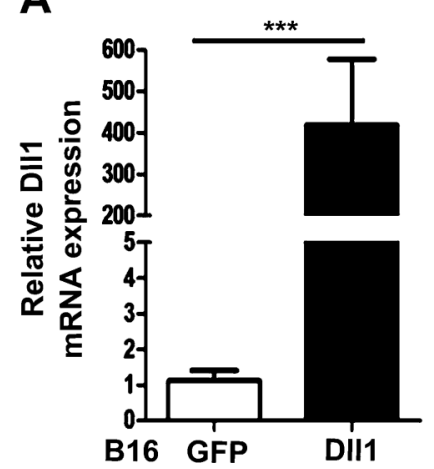

B

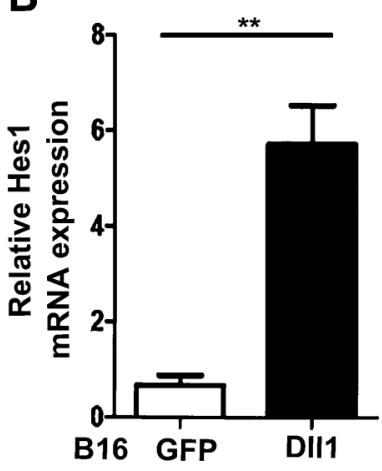

C

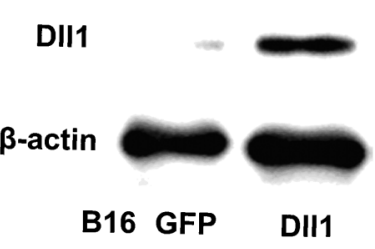

Figure 1. Overexpression of DII1 activated Notch signaling in B16 cells. A, Quantitative PCR revealed expression of DII1 mRNA in transfected cells. B, Expression of Notch down-stream gene Hes1 was observed in transfected B16 tumor cells. C, Dll1 protein was detected by Western blot in B16 tumor cells. Data are reported as means $\pm \mathrm{SD}$. ${ }^{* \star} \mathrm{P}<0.01,{ }^{* \star *} \mathrm{P}<0.001$, unpaired Student $t$-test, $\mathrm{n}=6$.

BD Immunocytometry Systems, USA). Data were analyzed using the CellQuest software.

\section{In vivo tumor cell adhesion assays}

All animal experiments were approved by the Animal Experiment Administration Committee of the Fourth Military Medical University. For in vivo tumor cell adhesion assays, C57BL/6 mice were injected with $5 \times 10^{5}$ melanoma cells through the tail vein and then killed after $2 \mathrm{~h}$. Ten minutes before the mice were killed, $100 \mu \mathrm{L}$ Evans blue was perfused through the tail vein to label pulmonary vasculature. After the lungs were harvested, they were sectioned at a thickness of $20 \mu \mathrm{m}$. The sections were observed using a laser scanning system (Radiance 2000; Bio-Rad Laboratories, USA) and a microscope (Eclipse TE300; Nikon, Japan), and GFP-labeled melanoma cells in the sections were counted. The number of GFP cells was normalized to the total examined surface area of the lung.

\section{Mouse model of lung metastasis}

To establish the lung metastasis model, tumor cells were trypsinized, suspended in PBS, and injected into the tail vein of C57BL/6 mice at a density of $5 \times 10^{5} / 200 \mu \mathrm{L}$ using a $30 \mathrm{G} 1 / 2$ needle and a $1-\mathrm{mL}$ syringe. Fourteen days after injection, the animals were weighed and killed. The lungs were removed, rinsed in PBS, and weighed. The lung weight index was calculated as the ratio of lung weight vs body weight. The harvested lungs were fixed in $10 \%$ neutral buffered formalin. Tumor foci on the surfaces of the lungs were counted under a stereomicroscope. Then, the whole lung was embedded in optimum cutting temperature compound (Sakura Finetek, USA), sectioned (12 $\mu \mathrm{m}$ thickness, 5 levels), and stained with hematoxylin and eosin (H\&E) according to routine protocols. Histological observations were performed under a microscope (BX51, Olympus, Japan). The percentage of total area of the stained sections occupied by tumor was measured using the Image-Pro Plus Phase 6 Imaging System (MediaCybernetics, USA).

\section{Statistical analysis}

Data are reported as means $\pm S D$ and were analyzed using the unpaired Student $t$-test (GraphPad Prism 5.0 for Windows, GraphPad Software, USA). P values less than 0.05 were considered to be statistically significant.

\section{Results}

\section{Overexpression of DII1 activated Notch signaling in $\mathrm{B} 16$ cells}

In preliminary experiments, we observed that, among four Notch receptors, only Notch1 could be detected by RT-PCR in B16 melanoma cells (Figure S1). Then, we introduced pIRES2-EGFP-DII1 plasmids or empty vectors into B16 cells to establish Dll1-overexpressing B16-DII1 cells and control B16-GFP cells (17). Real-time PCR revealed that the expression of DII1 in B16-DIl1 cells was significantly higher than that in B16-GFP cells (Figure 1A). The expression of murine Hes1 in cultured B16-DII1 cells was also upregulated, indicating that the Notch signaling was activated in these cells (Figure 1B). Western blot analysis confirmed DII1 protein expression in B16-DII1 cells (Figure 1C).

\section{Overexpression of DIl1 enhanced the adhesion of melanoma cells}

During our previous research (17), we noticed two interesting phenomena. First, B16-DIl1 cells were more difficult to detach from culture plates than control B16GFP cells under the same conditions. Second, B16-DIl1 cells tended to form aggregated colonies (Figure 2A). These observations suggest that DII1-mediated activation of Notch signaling may have some effects in facilitating 



Figure 2. DIl1 overexpression enhanced the adhesion capacity of tumor cells. A, Growth colonies of tumor cells were observed by seeding at low density. $B$, Plate adhesion assay. The bound tumor cells were assessed by 3-(4,5dimethylthiazol-2-yl)-2,5-diphenyltetrazolium bromide and compared. $C$, Endothelial cell (EC) adhesion assay. GFP-labeled tumor cells that adhered to EC were analyzed by flow cytometry. The total number of GFP-labeled cells was calculated based on flow cytometry shown in C. Data are reported as means $\pm \mathrm{SD}$. ${ }^{* *} \mathrm{P}<0.01$, ${ }^{* * *} \mathrm{P}<0.001$, unpaired Student $t$-test, $\mathrm{n}=4$.

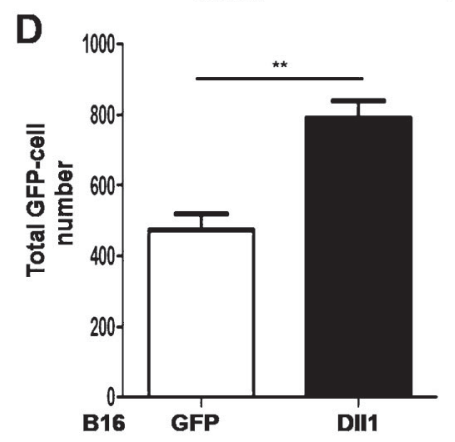

tumor cell adhesion. To test this hypothesis, in vitro adhesion assays were performed. As shown in Figure 2B, the number of cells adhering to the bottom of the plates was significantly higher for the B16-DIl1 group compared to the B16-GFP group. An endothelial cell adhesion assay was also carried out to determine whether overexpression of DII1 may contribute to heterotypic adhesion of tumor cells. Similar to the results of the plate adhesion assay, the number of B16-DIl1 cells adhering to HUVECs was significantly higher than that of B16-GFP cells (Figure 2C and D).

\section{Overexpression of DII1 led to tumor cell arrest in the lung}

Attachment of circulating tumor cells to lung endothelial cells is the initial step for lung metastasis. To investigate whether DIl1 expression could enhance tumor cell adhesion in vivo, we studied the initial fate of GFPlabeled control and B16-DII1 cells. Two hours after the
A

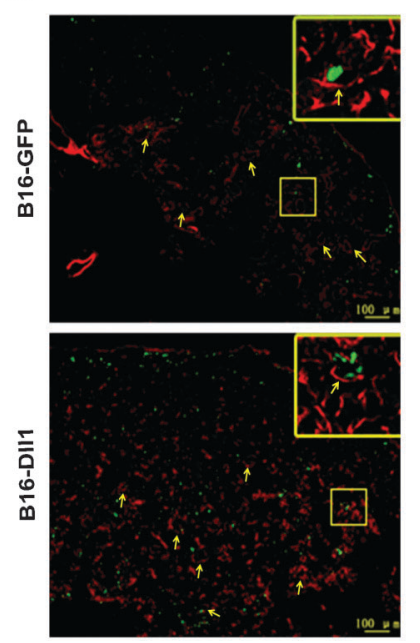

B

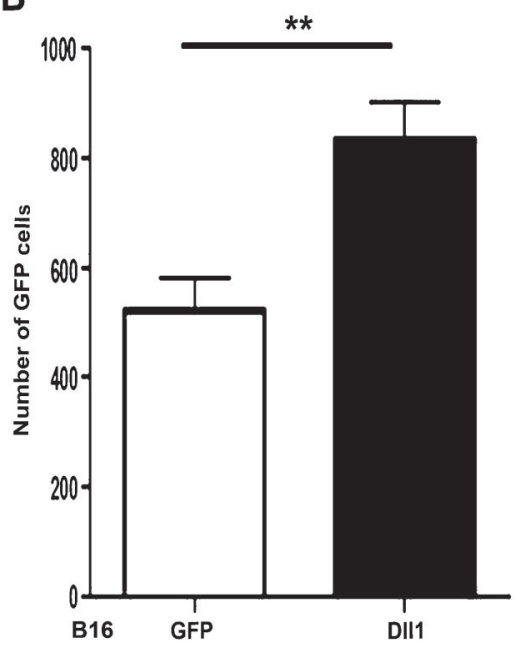

Figure 3. Overexpression of DIl1 led to tumor cell arrest in lung. $A$, Vessels of mouse lung were labeled with Evans blue (red) and sectioned, arrested GFP-labeled tumor cells (green) were detected with fluorescent microscope, at $40 \times$ magnification. Insets were amplified by laser scanning microscope at $200 \times$ magnification. Arrows indicate the vessels of mouse lung section. $B$, Average numbers of GFP-labeled tumor cells were counted in lung sections with the Image-Pro Plus Phase 6 Imaging System and compared. Data are reported as means $\pm \mathrm{SD}$. ${ }^{* *} \mathrm{P}<0.01$, unpaired Student $t$-test, $n=6$. 
A

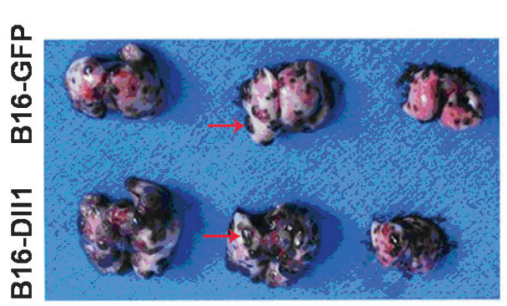

C

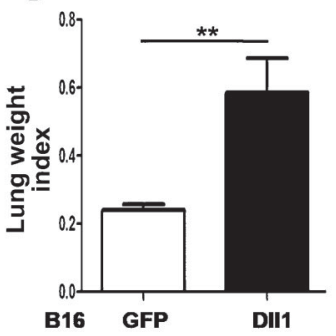

D

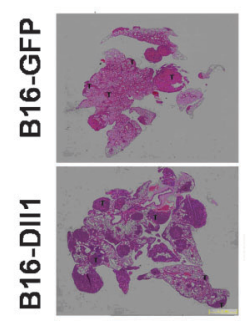

B

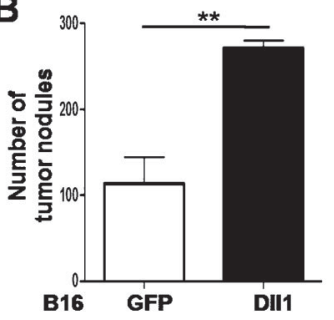

E

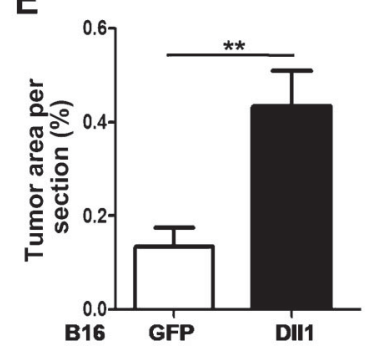

Figure 4. Overexpression of DIl1 promotes tumor metastasis in vivo. A, B16-DIl1 or B16GFP tumor cells were injected into the tail vein of normal mice. Lungs were dissected and photographed 15 days later. Tumor nodules are observed on the surface of lungs (red arrows). $B$, Tumor nodules on the surface of the lung were counted under a stereomicroscope and compared. $C$, Lung weight index was calculated as the ratio of lung weight versus body weight of host mice, and was compared between the two groups. $D$, Lungs in $A$ were sectioned and photographed with $\mathrm{H} \& \mathrm{E}$ staining. $T$ indicates the tumor foci in lungs. $E$, Tumor area in lung section was assessed by the Image-Pro Plus Phase 6 Imaging System and nomalized to total lung area. Data are reported as means \pm SD. ${ }^{* *} \mathrm{P}<0.01$, unpaired Student $t$-test, $\mathrm{n}=6$. tumor cells were intravenously injected, approximately twice as many B16-DIl1 tumor cells could be observed in the lungs compared to B16-GFP cells (Figure $3 \mathrm{~A}$ and $\mathrm{B}$ ). Furthermore, the B16-DIl1 cells in lung vessels tended to appear as aggregated pellets or tumor emboli, as shown in the magnified insets of Figure $3 \mathrm{~A}$.

\section{Overexpression of DIl1 promotes tumor metastasis in vivo}

To further investigate whether forced expression of DIl1 would affect tumor metastasis in vivo, we studied the metastatic potential of B16-DII1 and B16-GFP cells in mouse models of lung metastasis. Fifteen days after injection, lung samples were collected and tumor colonies on the surfaces of the harvested lungs were counted macroscopically
(Figure 4A). A dramatically increased number of tumor foci was observed in the lungs of B16-Dll1-injected mice compared to B16-GFP-injected mice (Figure 4B). Accordingly, the lung weight index indicated that metastasis was more remarkable for B16-DIl1 cells than B16-GFP cells (Figure 4C). Figure 4D and E shows H\&E staining of lung tumor tissue and the percentage of tumor area in comparison to total lung area. The results are in accordance with those of macroscopic observations.

\section{DIl1-mediated Notch activation induced N-cadherin expression}

Since Notch activation has been reported to influence cadherin expression, we hypothesized that enhanced
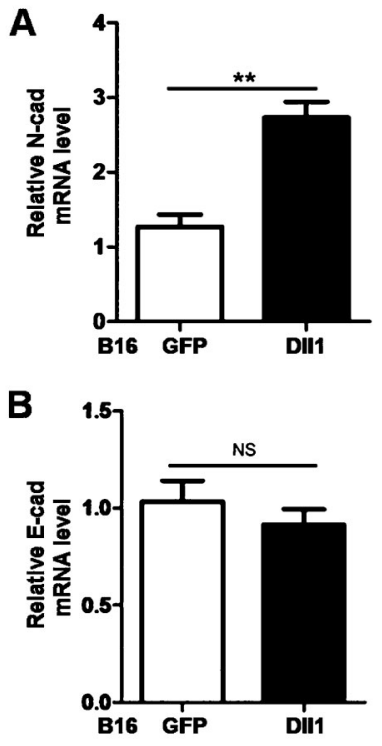

Figure 5. Dll1-mediated Notch activation induced $\mathrm{N}$-cadherin (cad) expression. The expressions of $\mathrm{N}$-cadherin $(A)$ and $\mathrm{E}$-cadherin $(B)$ were assessed by real-time RT-PCR, with $\beta$-actin as a reference control. $C$, The protein levels of Hes1, $\mathrm{N}$-cadherin, E-cadherin in tumor cells were examined with Western blot. Data are reported as means $\pm S D$. ${ }^{* *} \mathrm{P}<0.01$, unpaired Student $t$-test, $\mathrm{n}=6$. NS: not significant.

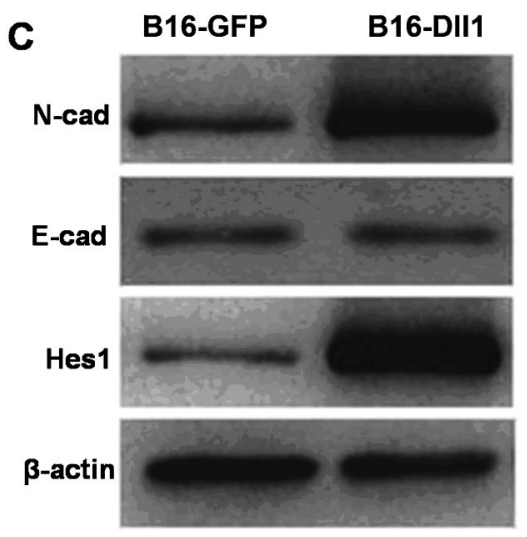


adhesion in B16-DIl1 cells may be attributed to the upregulation of cell surface cadherins. To test this hypothesis, we examined the expression of E-cadherin and $\mathrm{N}$-cadherin in B16-DII1 and B16-GFP cells. It was found that, along with DII1 overexpression, the level of $\mathrm{N}$-cadherin mRNA was remarkably increased in B16-DII1 cells, whereas the expression of E-cadherin showed no significant difference between B16-DII1 and B16-GFP cells (Figure $5 \mathrm{~A}$ and $\mathrm{B}$ ). Western blot analysis confirmed that Notch activation increased $\mathrm{N}$-cadherin expression without affecting E-cadherin expression (Figure 5C).

\section{Discussion}

Although modern surgical techniques and chemotherapeutic approaches have significantly improved the effectiveness of treatment in primary tumors, metastasis remains the leading cause of death in cancer patients (2). Therefore, defining the mechanisms underlying tumor metastasis is essential to improving cancer survival. Much effort has been devoted to identify prometastatic aberrations that constitute new therapeutic targets. Notch signaling is one of the most studied pathways involved in tumorigenesis, and increasing evidence indicates that the Notch pathway can function as a tumor promoter or suppressor, depending on the cell type and context (7). However, little is known about the role of Notch signaling in the development of metastasis in melanoma, a highly lethal malignancy notorious for its aggressive clinical course. During our previous research (17), we noticed that melanoma cells overexpressing the Notch ligand DII1 are difficult to detach from culture plates, indicating that Notch signaling might be involved in melanoma metastasis. In this study, by using the murine B16 melanoma cell line, we investigated the role of Notch ligand DIl1 in the adhesion and metastasis of melanoma cells, and it was found that overexpression of Dll1enhanced the adhesion and metastasis of melanoma cells both in vitro and in vivo.

To investigate the role of Notch ligand DIl1 in the metastasis of melanoma, we first established Dll1-overexpressing melanoma cells and compared their adhesion capacity with control cells in vitro using the plate adhesion assay and endothelial cell adhesion assay. Consistent with our previous observation that Dll1-overexpressing melanoma cells are more difficult to detach from culture plates, the results of the plate adhesion assay indicated that DII1 overexpression significantly increased the number of adhering tumor cells. Our results also indicated that DII1 overexpression may promote homotypical adhesion, since B16-DIl1 melanoma cells tended to form aggregated colonies. Because attachment of circulating tumor cells to lung endothelial cells is the initial step for lung metastasis (18), the adhesion ability of Dll1-overexpressing melanoma cells was further investigated using the endothelial cell adhesion assay. The finding that B16DII1 melanoma cells exhibited a higher adhesion ability than endothelial cells implies that DII1 may enhance the metastasis of melanoma, since the adhesion of circulating tumor cells to vascular endothelial cells is one of the key steps in metastasis.

To further confirm the adhesion-promoting effects of DIl1 in vivo, we compared the number of adhering control and B16-DII1 cells in the lung vascular system after injection of the tumor cells. In accordance with the results of the in vitro endothelial cell adhesion assay, in vivo studies revealed a higher number of arrested melanoma cells in the lungs. Furthermore, the observation that the arrested B16-DII1 cells tended to form aggregates implies a higher metastatic potential of these cells because it is easier for aggregated tumor cells to colonize in the targeting tissue and thus develop into metastatic lesions.

The higher metastatic potential of DII1-overexpressing melanoma cells was eventually confirmed using a mouse model of lung metastasis. Compared with the control group, mice injected with B16-DII1 cells exhibited an increased number of metastatic foci, a higher lung weight index, and greater relative tumor area. These results are in agreement with recent reports about other malignant tumors. Aberrant Notch expression has been reported to be closely associated with tumor progression and poor clinical outcomes in prostate cancer, gastric cancer, and osteosarcoma $(19,20)$. Although Jagged1-mediated Notch activation promoted breast cancer invasion and metastasis (21), targeted knockdown of Notch1 inhibited tumor cell invasion in pancreatic cancer and prostate cancer $(22,23)$.

The increased metastatic ability of B16-DIl1 cells suggests that particular adhesion molecules may be induced after activation of Notch signaling. Cadherins are a family of $\mathrm{Ca}^{2+}$-dependent homotypic and heterotypic adhesion molecules participating in the regulation of cell-cell interactions during tissue development and carcinogenesis (24). Loss of E-cadherin and the presence of $\mathrm{N}$-cadherin are required for tumor invasion and metastasis in melanoma and other epithelial-derived carcinomas (25-28). Upregulation of $\mathrm{N}$-cadherin in human melanoma was found to be sufficient to mediate adhesion of tumor cells to endothelial cells and to facilitate distant metastasis $(29,30)$. Since DII1 has been reported to be associated with the $\mathrm{N}$-cadherin- $\beta$-catenin complex in cellto-cell adhesion junctions (31), and induction of cadherin expression has been indicated after activation of Notch signaling $(21,32)$, we hypothesized that Dll1 overexpression may enhance tumor metastasis by upregulation of $\mathrm{E}$-cadherin and $\mathrm{N}$-cadherin in melanoma cells. RT-PCR and Western blot analysis found that, along with DIl1 overexpression and Notch activation, the expression of $\mathrm{N}$ cadherin was significantly upregulated in DII1-B16 cells, whereas the expression of E-cadherin remained unchanged. Upregulation of $\mathrm{N}$-cadherin may enhance metastasis of melanoma cells through the combined effects of several mechanisms. First, upregulation of 
$\mathrm{N}$-cadherin may result in effective attachment of tumor cells to lung endothelial cells and thus protect them from anoikis $(33,34)$. Second, $\mathrm{N}$-cadherin may promote the migration of tumor cells through endothelial cells $(29,30,35)$. Third, N-cadherin may facilitate tumor cell survival and proliferation in a new environment (36).

In conclusion, the data from this research indicated that overexpression of DII1 could potentiate the adhesion and metastasis of melanoma through the upregulation of $\mathrm{N}$-cadherin expression. These results suggested that the Notch ligand DII1 may be a target for developing effective strategies to reduce metastasis in melanoma. Besides upregulation of $\mathrm{N}$-cadherins, overexpression of DIl1 may also enhance the metastasis of melanoma cells by

\section{References}

1. Finn L, Markovic SN, Joseph RW. Therapy for metastatic melanoma: the past, present, and future. BMC Med 2012; 10: 23, doi: 10.1186/1741-7015-10-23.

2. Eccles SA, Welch DR. Metastasis: recent discoveries and novel treatment strategies. Lancet 2007; 369: 1742-1757, doi: 10.1016/S0140-6736(07)60781-8.

3. Yilmaz M, Christofori G, Lehembre F. Distinct mechanisms of tumor invasion and metastasis. Trends Mol Med 2007; 13: 535-541, doi: 10.1016/j.molmed.2007.10.004.

4. Fidler IJ. The pathogenesis of cancer metastasis: the 'seed and soil' hypothesis revisited. Nat Rev Cancer 2003; 3: 453458, doi: $10.1038 / \mathrm{nrc} 1098$.

5. Lafrenie RM, Buchanan MR, Orr FW. Adhesion molecules and their role in cancer metastasis. Cell Biophys 1993; 23: 3-89, doi: 10.1007/BF02796507.

6. Kato $\mathrm{H}$, Taniguchi $\mathrm{Y}$, Kurooka $\mathrm{H}$, Minoguchi $\mathrm{S}$, Sakai $\mathrm{T}$, Nomura-Okazaki S, et al. Involvement of RBP-J in biological functions of mouse Notch1 and its derivatives. Development 1997; 124: 4133-4141.

7. Bolos V, Grego-Bessa J, De La Pompa JL. Notch signaling in development and cancer. Endocr Rev 2007; 28: 339-363, doi: 10.1210/er.2006-0046.

8. Baia GS, Stifani S, Kimura ET, McDermott MW, Pieper RO, Lal A. Notch activation is associated with tetraploidy and enhanced chromosomal instability in meningiomas. Neoplasia 2008; 10: 604-612.

9. Zage PE, Nolo R, Fang W, Stewart J, Garcia-Manero G, Zweidler-McKay PA. Notch pathway activation induces neuroblastoma tumor cell growth arrest. Pediatr Blood Cancer 2012; 58: 682-689, doi: 10.1002/pbc.23202.

10. Curry CL, Reed LL, Golde TE, Miele L, Nickoloff BJ, Foreman KE. Gamma secretase inhibitor blocks Notch activation and induces apoptosis in Kaposi's sarcoma tumor cells. Oncogene 2005; 24: 6333-6344.

11. Massi D, Tarantini F, Franchi A, Paglierani M, Di Serio C, Pellerito $S$, et al. Evidence for differential expression of Notch receptors and their ligands in melanocytic nevi and cutaneous malignant melanoma. Mod Pathol 2006; 19: 246254, doi: 10.1038/modpathol.3800526.

12. Hoek K, Rimm DL, Williams KR, Zhao H, Ariyan S, Lin A, et al. Expression profiling reveals novel pathways in the transformation of melanocytes to melanomas. Cancer Res 2004; 64: interaction with its receptor and may serve as an adhesion molecule by itself (37). Therefore, the detailed mechanism of DII1-related enhancement of melanoma metastasis needs to be further investigated.

\section{Supplementary Material}

Click here to view [pdf].

\section{Acknowledgments}

Research supported by grants from the Natural Science Foundation of China (\#81272072 and \#30901784).

5270-5282, doi: 10.1158/0008-5472.CAN-04-0731

13. Pinnix CC, Lee JT, Liu ZJ, McDaid R, Balint K, Beverly LJ, et al. Active Notch1 confers a transformed phenotype to primary human melanocytes. Cancer Res 2009; 69: 53125320, doi: 10.1158/0008-5472.CAN-08-3767.

14. Bedogni B, Warneke JA, Nickoloff BJ, Giaccia AJ, Powell MB. Notch1 is an effector of Akt and hypoxia in melanoma development. J Clin Invest 2008; 118: 3660-3670, doi: 10.1172/JCI36157.

15. Balint K, Xiao M, Pinnix CC, Soma A, Veres I, Juhasz I, et al. Activation of Notch1 signaling is required for beta-cateninmediated human primary melanoma progression. J Clin Invest 2005; 115: 3166-3176, doi: 10.1172/JCI25001.

16. Liu ZJ, Xiao M, Balint K, Smalley KS, Brafford P, Qiu R, et al. Notch1 signaling promotes primary melanoma progression by activating mitogen-activated protein kinase/phosphatidylinositol 3-kinase-Akt pathways and up-regulating $\mathrm{N}$-cadherin expression. Cancer Res 2006; 66: 4182-4190, doi: 10.1158/0008-5472.CAN-05-3589.

17. Zhang JP, Qin HY, Wang L, Liang L, Zhao XC, Cai WX, et al. Overexpression of Notch ligand DIl1 in B16 melanoma cells leads to reduced tumor growth due to attenuated vascularization. Cancer Lett 2011; 309: 220-227, doi: 10.1016/ j.canlet.2011.06.008.

18. Behrens J. The role of cell adhesion molecules in cancer invasion and metastasis. Breast Cancer Res Treat 1993; 24: 175-184, doi: 10.1007/BF01833258.

19. Yeh TS, Wu CW, Hsu KW, Liao WJ, Yang MC, Li AF, et al. The activated Notch1 signal pathway is associated with gastric cancer progression through cyclooxygenase-2. Cancer Res 2009; 69: 5039-5048, doi: 10.1158/00085472. CAN-08-4021.

20. Santagata S, Demichelis F, Riva A, Varambally S, Hofer MD, Kutok JL, et al. JAGGED1 expression is associated with prostate cancer metastasis and recurrence. Cancer Res 2004; 64: 6854-6857, doi: 10.1158/0008-5472.CAN-042500.

21. Leong KG, Niessen K, Kulic I, Raouf A, Eaves C, Pollet I, et al. Jagged1-mediated Notch activation induces epithelialto-mesenchymal transition through Slug-induced repression of E-cadherin. J Exp Med 2007; 204: 2935-2948, doi: 10. 1084/jem.20071082. 
22. Wang Z, Banerjee S, Li Y, Rahman KM, Zhang Y, Sarkar $\mathrm{FH}$. Down-regulation of notch-1 inhibits invasion by inactivation of nuclear factor-kappaB, vascular endothelial growth factor, and matrix metalloproteinase-9 in pancreatic cancer cells. Cancer Res 2006; 66: 2778-2784, doi: 10.1158/00085472.CAN-05-4281.

23. Bin Hafeez B, Adhami VM, Asim M, Siddiqui IA, Bhat KM, Zhong $W$, et al. Targeted knockdown of Notch1 inhibits invasion of human prostate cancer cells concomitant with inhibition of matrix metalloproteinase- 9 and urokinase plasminogen activator. Clin Cancer Res 2009; 15: 452459, doi: 10.1158/1078-0432.CCR-08-1631.

24. Vleminckx K, Kemler R. Cadherins and tissue formation: integrating adhesion and signaling. Bioessays 1999; 21: 211-220, doi: 10.1002/(SICI)1521-1878(199903)21:3<211:: AID-BIES5 $>3.0 . \mathrm{CO} ; 2-\mathrm{P}$.

25. Hazan RB, Qiao R, Keren R, Badano I, Suyama K. Cadherin switch in tumor progression. Ann N Y Acad Sci 2004; 1014: 155-163, doi: 10.1196/annals.1294.016.

26. Hirohashi S. Molecular aspects of adhesion-epigenetic mechanisms for inactivation of the E-cadherin-mediated cell adhesion system in cancers. Verh Dtsch Ges Pathol 2000; 84: 28-32.

27. Nieman MT, Prudoff RS, Johnson KR, Wheelock MJ. $\mathrm{N}$-cadherin promotes motility in human breast cancer cells regardless of their E-cadherin expression. J Cell Biol 1999; 147: 631-644, doi: 10.1083/jcb.147.3.631.

28. Suyama K, Shapiro I, Guttman M, Hazan RB. A signaling pathway leading to metastasis is controlled by $\mathrm{N}$-cadherin and the FGF receptor. Cancer Cell 2002; 2: 301-314, doi: 10.1016/S1535-6108(02)00150-2.

29. Sandig M, Voura EB, Kalnins VI, Siu CH. Role of cadherins in the transendothelial migration of melanoma cells in culture. Cell Motil Cytoskeleton 1997; 38: 351-364, doi: 10.1002/
(SICI)1097-0169(1997)38:4<351::AID-CM5>3.0.CO;2-6.

30. Qi J, Chen N, Wang J, Siu CH. Transendothelial migration of melanoma cells involves $\mathrm{N}$-cadherin-mediated adhesion and activation of the beta-catenin signaling pathway. Mol Biol Cell 2005; 16: 4386-4397, doi: 10.1091/mbc.E05-030186.

31. Mizuhara E, Nakatani $T$, Minaki $Y$, Sakamoto $Y$, Ono $Y$, Takai Y. MAGI1 recruits DII1 to cadherin-based adherens junctions and stabilizes it on the cell surface. J Biol Chem 2005; 280: 26499-26507, doi: 10.1074/jbc.M500375200.

32. Garcia A, Kandel JJ. Notch: a key regulator of tumor angiogenesis and metastasis. Histol Histopathol 2012; 27 151-156.

33. Rangarajan A, Syal R, Selvarajah S, Chakrabarti O, Sarin A, Krishna S. Activated Notch1 signaling cooperates with papillomavirus oncogenes in transformation and generates resistance to apoptosis on matrix withdrawal through $\mathrm{PKB} /$ Akt. Virology 2001; 286: 23-30, doi: 10.1006/viro.2001. 0867.

34. Hu YY, Zheng MH, Zhang R, Liang YM, Han H. Notch signaling pathway and cancer metastasis. Adv Exp Med Biol 2012; 727: 186-198, doi: 10.1007/978-1-4614-0899-4_14.

35. Qi J, Wang J, Romanyuk O, Siu CH. Involvement of SrC family kinases in $\mathrm{N}$-cadherin phosphorylation and betacatenin dissociation during transendothelial migration of melanoma cells. Mol Biol Cell 2006; 17: 1261-1272, doi: 10.1091/mbc.E05-10-0927.

36. Li G, Satyamoorthy K, Herlyn M. N-cadherin-mediated intercellular interactions promote survival and migration of melanoma cells. Cancer Res 2001; 61: 3819-3825.

37. Murata A, Okuyama K, Sakano S, Kajiki M, Hirata T, Yagita $\mathrm{H}$, et al. A Notch ligand, Delta-like 1 functions as an adhesion molecule for mast cells. J Immunol 2010; 185: 3905-3912, doi: 10.4049/jimmunol.1000195. 